\title{
Assessment of explosion risk for wood dust in a ventilation-dust separation installation, by determining the concentration of total dust in suspension inside of the installation
}

\author{
Marius Kovacs $^{1 *}$, Lorand Toth ${ }^{1}$, and Sorin Simion ${ }^{1}$ \\ ${ }^{1}$ National Institute for Research and Development in Mine Safety and Protection to Explosion - \\ INSEMEX Petroşani, Romania
}

\begin{abstract}
Most of combustible dusts present both fire and explosion hazard. Explosion may occur at certain concentrations of dust mixed with air and in the presence of an ignition source. The threat posed by this real danger was confirmed by the events that took place in economic units such as: feed factories, wood products, textile industry, steel, etc. Among the parameters of explosiveness of combustible dust, which can cause an explosion, we mention: maximum explosion pressure, lower explosion limit, explosive index, minimum ignition energy, electrical resistivity of dust, minimum ignition temperature of dust layer and cloud, particle size and concentration of dust in suspension. The current paper presents the results of determinations of combustible wood dust concentrations, performed at an important economic unit, manufacturing veneer and wood panels, at a dusting ventilation installation composed of fan, cyclone and textile filter. These determinations were made in the pipe connecting the fan and the bag filter, to assess possible danger of explosion in the pipe, by relating the measured concentration to the lower explosion limit (concentration of wood dust).
\end{abstract}

\section{General information on explosion danger of combustible dusts}

Dust explosion has different characteristics compared to gas explosion, and can be, in some cases, much more devastating. If, for example, a stream of air swirls a layer of dust in a small space, dust along with oxygen forms a combustible dust / air mixture. If this mixture is initiated by an ignition source, the explosion is triggered, which in turn swirls more dust in the air, thus amplifying the effects of the explosion [1].

New concepts of explosion prevention and protection develop new strategies to prevent the spread of explosions or limit the effects of explosions, which requires consideration of aspects related to closure (limitation, restriction, delimitation, encapsulation) of explosive mixtures. Consideration must also be given to the fact that in order to consider a dust to be fuel, it must be explosive - be suspended in air, have a particle size distribution capable of propagating combustion and a concentration within explosive limits.

*Corresponding author: marius.kovacs@insemex.ro 
Usually, the requirement to prevent explosions can be expressed as follows: the probability of an ignition source occurring at the same time as an explosive atmosphere to be minimal [1]. It follows that, specific requirements are set for protective equipment and systems for specific areas of use. For applying this principle, Ex hazardous non-mining areas are classified into regions depending on probability and duration of the explosive atmosphere (regions 0,1 and 2 for gases and 20,21, 22 for combustible dusts in the air), and the equipment is divided into categories according to the level of protection provided, by avoiding sources of initiation during normal operation, during foreseeable failures or during rare failures.

Classification of hazardous areas into regions is the responsibility of employers, users of equipment and is regulated by Directive 1999/92/EC transposed in GD 1058/2006, and classification of equipment into categories corresponding to level of protection provided is the responsibility of manufacturers, as regulated in Directive 2014/34/EU transposed in GD 245/2016 [2]. According to the ATEx Directives, the responsibility for risk assessment and taking appropriate protection measures to ensure an acceptable level of safety lies with both equipment manufacturers and their users.

\section{The wood processing activity}

The economic unit under analysis carries out, as main activities, manufacturing of veneer and wood panels, (CAEN code 1621) and collection of non-hazardous waste (CAEN code 3811) [4].

Main construction structures:

- production and storage hall,

- utility building, workshop, transformer, sprinkler station,

- shredder buildings and

- adhesive hall.

The following types of wood-based panels are produced in the existing installations within the unit:

- wood chipboard, called "OSB" (oriented pool board) and

- chipboard or fibreboard.

2.1. Within the technological flow of manufacturing OSB type boards, the following basic operations are performed: supply and storage of raw materials, preparation of wet chips (peeling and chopping logs), drying of chips, preparation of dry chips (sorting), preparation of adhesive (dosing and mixing resins and additives), production of wood-based boards (mixing chips with adhesive, forming carpet chips, hot pressing, cooling), finishing (transverse and longitudinal formatting, sealing the edges of OSB type boards, feather and groove milling, as appropriate), packaging, storage and delivery of finished products to internal and external partners with whom the company has commercial relations.

As installations / equipment for OSB production we mention:

- transport equipment: transverse feed conveyors, scraper lifts, belt conveyors, chain conveyors, scraper conveyors, auger conveyors, handling cranes, push carts;

- peeling equipment: Rotary peeler;

- chopping machine: OSB shredder;

- chip dryer: TT 7 rotary dryer;

- sorting equipment: sieve;

- adhesive dosing and application plant: storage containers, supply pumps, dosing stations, pipeline network, adhesive application drum;

- postforming: dosing hopper, pressing rollers, magnetic separator;

- forming line: edging unit; 
- pressing plant: pressing equipment with temperature control circuit;

- forming equipment: plate cooler, diagonal saw, longitudinal saw, cross-saw, roller and chain conveyors, stacking lifts, saw feeders,

- OSB plate grinder;

- feather and groove processing plant: longitudinal cutting saw;

- metal detector;

- packaging system: metal strip cover, foil applicator, cross-winding machine;

- storage silo;

- thermal oil heating system to supply the required temperature to the press;

- electrical installations and AMC;

- pneumatic transport installation;

- exhaust installations: cyclones, filters with jet-pulse bags, electro filter.

2.2. The following is performed in the technological flow of chipboards basic manufacturing operations: preparation of chips for chipboard (peeling, chopping, drying), sorting of chips, mixing of chips with adhesive, carpet forming and pressing, transverse and longitudinal formatting, cooling, grinding, packaging, storage and delivery of the finished product to internal and external partners with whom the company has commercial relations [4].

As installations / equipment for the manufacture of chipboards we mention:

- transport equipment;

- sorting equipment: vibrating screen;

- storage silos;

- adhesive dosing system;

- carpet installation;

- prepress plant;

- forming plant: saw cut into a carpet;

- press installation: press loader, press unloader, press rollers;

- formatting installation: formatting saws;

- cooling system;

- electrical installations and AMC;

- pneumatic transport installation;

- exhaust installations: cyclones, filters with jet-pulse bags.

\subsection{Other activities carried out on site:}

- collecting biomass and biomass-like waste;

- diesel storage;

- water supply for drinking, sanitary and industrial uses;

- storage of finished products, raw materials and auxiliary materials;

- transport by factory rail;

- car transport of (non-hazardous) goods;

- industrial air compression;

- operation, maintenance and repairing of equipment and installations related to the site;

- testing activities of raw materials, intermediate and finished products, and

- administrative activities. 


\section{Investigations carried out to determine the concentrations of wood dust in the ventilation - dust removal installation of the economic unit}

\subsection{Presentation of the ventilation dust removal installation}

In order to ensure optimal working conditions for employees, respectively their exposure to wood dust concentrations below the limits allowed by regulations in force, the wood chopping section is equipped with dust removal ventilation installations.

Retention of the wood dust conveyed through pipes, by pneumatic transport by a fan, is performed in two separation stages, cyclone for coarse dust and bag filters for fine dust, photo no.1.

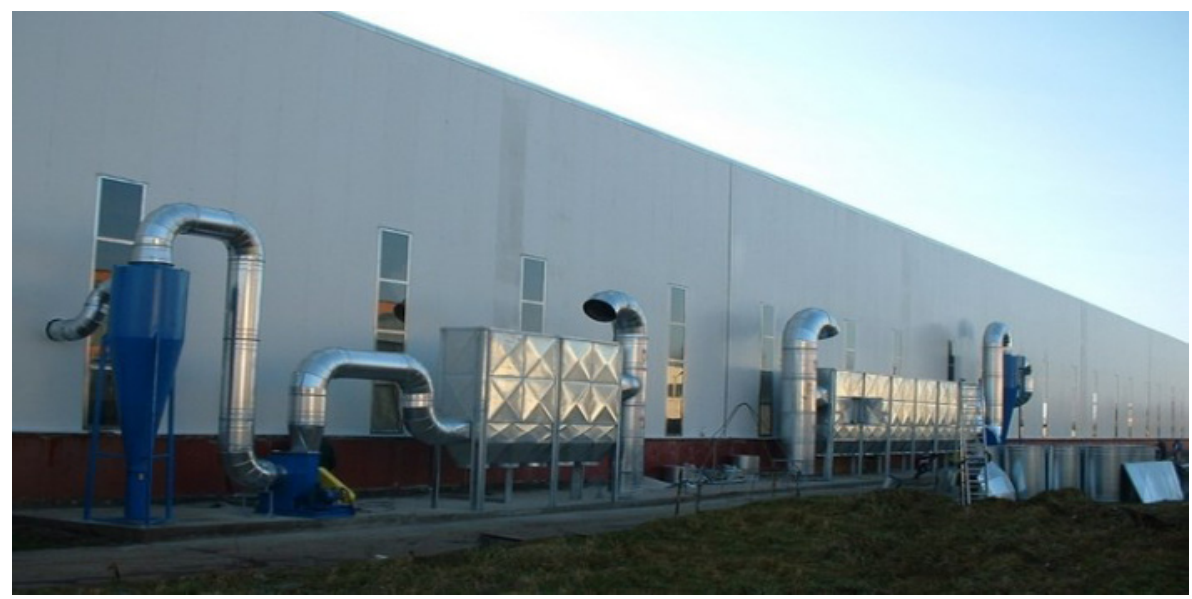

Fig 1. Dust ventilation- dust removal system. General view.

The main components and connecting parts of the ventilation - dust removal installation, within the wood shredding section, are:

- closed hood suction systems, located at each working point where suspended dust is released;

- pipes connecting hoods and the CLA6-2500Cyclone, as the first stage of separation of coarse dust;

- the connecting pipe between the cyclone and the Fan, which ensures a flow rate of $34300 \mathrm{~m}^{3} / \mathrm{h}$ inside the installation;

- connecting pipe between the fan and the CDRW12-05-3375-03jet-pulse textile filter, as the second stage of separating fine dust,

- pipe for exhausting purified air into the atmosphere of the unit.

\subsection{The technique for measuring dust in the installation}

A large number of accidental dust explosions have happened and found in literature since 1785 [3]

In order to determine the risk of explosion of wood dust in the installation, dust samples were collected from the pipe connecting the cyclone and the fan, which will be compared with the lower explosive limit, (minimum explosive concentration) [5].

As the speed of dusty air in the pipe is high (over $10 \mathrm{~m} / \mathrm{s}$ ) it is necessary to observe the isokinetic sampling, i.e., in the sampling section the speed should be equal to that in the pipe. 
The ISOSTACK BASIC SAMPLER device, equipped with an isokinetic probe and the TECORA TCR system, endowment on INSEMEX Petrosani, was used for sampling dust from the pipe of the dust ventilation installation.

Components and the sampling scheme are shown in fig. no. 2, and the TECORA TCR system in fig. no.3.

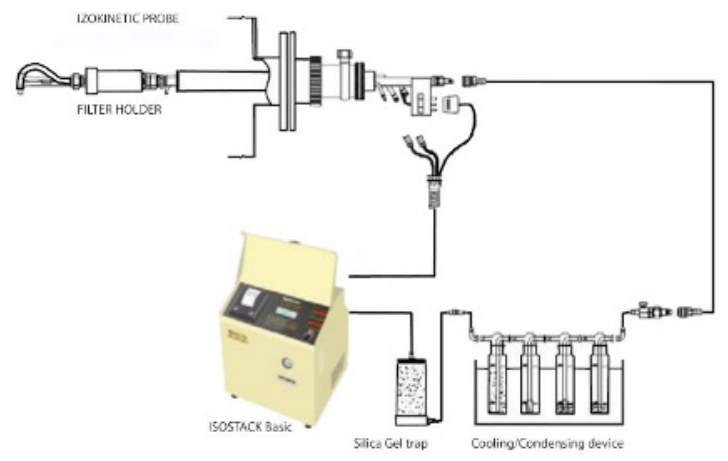

Fig 2. Sampling scheme using the isokinetic probe

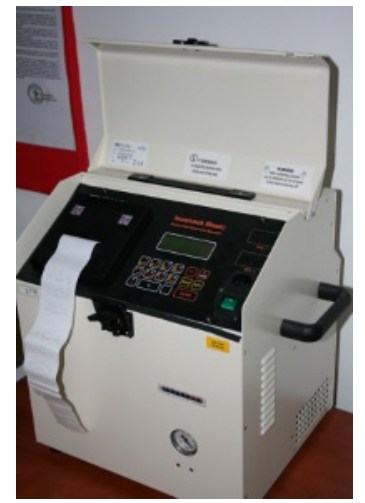

Fig. 3. TECORA TCR system

The device complies with SR EN 9096/2005 and consists of basic equipment, connectors and accessories. [6], [7]

The device consists of: keyboard and display, built-in printer, flow meter, thermostat, barometer thermocouple connector, RS 232 connector, two-way Pa / Pam and $\Delta \mathrm{p}$ connector, auxiliary temperature connectors and thermosetting connectors. [8]

Device software allows automatic data processing and display of test reports.

\subsection{Results of measurements performed}

After performing 3 determinations of total wood dust concentrations in 3 phases, with the ISOSTACK BASIC SAMPLER device, in pipe connecting the cyclone and the installation fan, the results shown in table no. 1 were obtained. 
Tabel 1. Phases of dust determinations

\begin{tabular}{|c|c|c|c|c|c|c|}
\hline \multirow{2}{*}{$\begin{array}{l}\text { Sampling } \\
\text { place }\end{array}$} & \multirow{2}{*}{$\begin{array}{l}\text { Measured } \\
\text { parameter }\end{array}$} & \multirow{2}{*}{$\begin{array}{l}\text { Measurement } \\
\text { phase }\end{array}$} & \multicolumn{3}{|c|}{ Measured dust concentrations, $\mathrm{g} / \mathrm{mc}$} & \multirow[b]{2}{*}{$\begin{array}{l}\text { Auxiliar } \\
\text { parameters }\end{array}$} \\
\hline & & & $\begin{array}{l}\text { in samples taken at } \\
30 \text { minutes }\end{array}$ & $\begin{array}{l}\text { Sample } \\
\text { average / } \\
\text { phase }\end{array}$ & $\begin{array}{l}\text { Average } \\
\text { of } \\
3 \text { phases }\end{array}$ & \\
\hline \multirow{9}{*}{$\begin{array}{l}\text { The pipe } \\
\text { connecting th } \\
\text { cyclone and } \\
\text { the fan }\end{array}$} & \multirow{9}{*}{$\begin{array}{l}\text { Wood dust } \\
\text { in } \\
\text { suspension }\end{array}$} & \multirow[t]{3}{*}{ I } & 0,07644 & \multirow{3}{*}{0,07338} & \multirow{9}{*}{0,07032} & \multirow{9}{*}{$\begin{array}{c}\mathrm{H}=1 \mathrm{~m} \\
\mathrm{D}=1 \mathrm{~m} \\
\mathrm{Ts}=22,6^{0} \mathrm{C} \\
\mathrm{Va}=11,07 \\
\mathrm{~m} / \mathrm{s} \\
\mathrm{W}=39,2 \%\end{array}$} \\
\hline & & & 0,07143 & & & \\
\hline & & & 0,07227 & & & \\
\hline & & II & 0,06555 & \multirow{3}{*}{0,06837} & & \\
\hline & & & 0,0699 & & & \\
\hline & & & 0,06966 & & & \\
\hline & & \multirow[t]{3}{*}{ III } & 0,07227 & \multirow{3}{*}{0,06921} & & \\
\hline & & & 0,06726 & & & \\
\hline & & & 0,0681 & & & \\
\hline
\end{tabular}

Notes / observations / findings:

Auxiliary parameters: H- Pipe height; D - Pipe diameter; Ts - Duct air temperature; VAir velocity in the duct; $\mathrm{W}$ - effluent humidity.

Concentrations were normalized according to temperature, pressure and humidity.

$\mathrm{No}_{2}$ and $\mathrm{CO}_{2}$ determinations were performed because there was no combustion process.

During dust sampling the technological processes took place under normal operating conditions.

The method of determination was in accordance with PS - 13 of the test laboratory.

Measurement uncertainty, $\mathrm{Ue}= \pm 1.3 \mathrm{mg} / \mathrm{Nm}^{3}$

Graphical representation of the variation of concentrations determined in the 3 phases of measurements and their averages are shown in fig. no. 4.

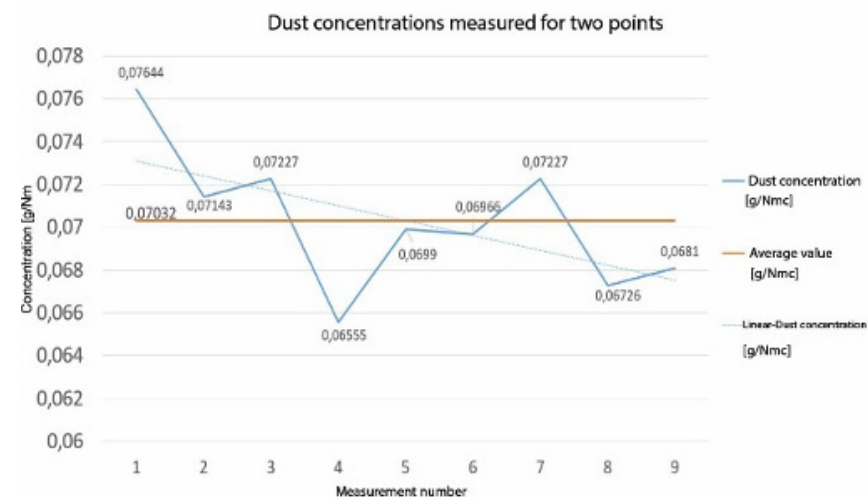

Fig. 4. Variation of measured concentrations

\section{Interpretation of results}

Analysing data shown in table no. 1 the following resulted:

- none of the concentration of wood dust determined in the pipe exceeded the lower limit of explosiveness (minimum explosion concentration), of $20 \mathrm{~g} / \mathrm{m}^{3}$, all having values much lower than the mentioned limit.

- the average of the 9 concentration measurements was $0.070323 \mathrm{mg} / \mathrm{m}^{3}$.

Consequently, the risk of explosion in the analysed installation is very low. 


\section{Conclusions}

New concepts related to prevention and protection in case of combustible dusts explosion, establish a series of specific requirements for equipment and protective systems in the respective fields.

Most of combustible dusts present both fire and explosion hazard. Explosion may occur at certain concentrations of dust mixed with air and in the presence of an ignition source.

To determine the risk of wood dust explosion in the technological process, investigations were carried out at an economic unit that manufactures veneer and wood panels.

In this sense, samples of wood dust were collected from the pipe connecting the cyclone and the fan, and results obtained were compared with the lower explosive limit, determined by the specialized laboratory within INSEMEX.

The measurements showed that none of the concentration of wood dust determined in the pipe exceeded the lower limit of explosiveness (minimum explosion concentration), of 20 $\mathrm{g} / \mathrm{m}^{3}$, all having values much lower than the mentioned limit.

Consequently, the risk of explosion in the analysed installation is very low.

As a recommendation, we consider that it would be appropriate to carry out periodic determinations of dust concentrations at critical points in technological flows of combustible products, where suspended dust is released, to genuinely assess the risk of explosion.

From the measurements performed, it results that the risk of explosion in the analyzed installation is reduced, due to the fact that no concentration of wood dust determined in the instalation did not exceed the lower explosive limit for this type of dust of $20 \mathrm{~g} / \mathrm{m}^{3}$.

\section{References}

1. George Artur Gaman, el.al., National guide on establishing occupational safety and health requirements for economic agents operating with substances / products / goods able of generating explosive / toxic atmospheres or having detonating / explosive characteristics, INSEMEX Publishing House, Petrosani, 2018, ISBN* 978-606-8761- 26-8.

2. Gyenes, Zsuzsanna, Maureen Heraty, Struckl, Michael - Handbook of Scenarios for Assessing Major Chemical Accident Risks, 2017

3. Wan Zaiton Wan Sulaiman, Rafiziana Md Kasmani - An Overview Of Explosion Severity On Dust Explosion- Jurnal Teknologi, Electronic ISSN $\quad 2180-3722-2011$

4. Integrated environmental permit no. SB 127 of 12.10 .2011 , issued by the Ministry of Environment - National Agency for Environmental Protection Brasov.

5. ORDER no. 176 of February 15, 2005 on the approval of the Technical Regulation "Norm for the design, execution, verification and operation of electrical installations in areas with danger of explosion", indicative NP 099-04

6. SR EN 15259:2009 - Air quality. Measurement of emissions from fixed sources. Requirements for measurement sections and locations, as well as the measurement objective, plan and report.

7. Law no. $278 / 2013$ on industrial emissions.

8. Order 462/1993: Methodological norm regarding the determination of emissions of air pollutants produced by stationary sources 